\title{
Development of a route conversion program for antimicrobial agents at the Toronto Hospital
}

\author{
MONIQUE PITRE BScPhm, MONIQUE ZAMIN BScPhm, JOHN CONLY MD
}

$I_{\circ}^{N}$ N THE 1990S HOSPITALS FACE THE TREMENDOUS CHALLENGE of providing optimal patient care with limited funds. Drug products and related costs represent a considerable portion of institutional expenditures. Since antimicrobial agents commonly consume 20 to $40 \%$ of a hospital drug budget, they are frequently the focus of cost-containment efforts.

At The Toronto Hospital, several strategies are currently employed by the antibiotic subcommittee to promote the cost-effective use of antimicrobials, including the following: the maintenance of a controlled formulary system of selected antimicrobials, guidelines for the use of specific antimicrobials and restriction of antimicrobials to specific prescribers or disease states. During 1994 the dosage interval and dose of selected antimicrobials was extended or modified based on a review of relevant literature, including appropriate pharmacokinetic and pharmacodynamic studies. As a result, changes were made for dosing recommendations for cefotaxime, piperacillin and aminoglycosides. All guidelines and recommendations are published yearly in a handbook distributed to all prescribing physicians.

To complement the efforts of the antibiotic subcommittee in the promotion of appropriate use of antimicrobials, a formal route conversion program was piloted and implemented in the spring of 1994 as part of a pharmacy residency project. The program consisted of written guidelines for route conversion based on disease states and antimicrobial agents, a facts sheet outlining the benefits of oral therapy and an education program for pharmacists and prescribing physicians. The guidelines included patient selection criteria for

Section of Infectious Diseases, Department of Medicine and Department of Pharmacy Services, The Toronto Hospital. Toronto, Ontario

Correspondence: Dr John M Conly. Section of Infectious Diseases, Department of Medicine, The Toronto Hospital, NU 13-117, 585 University Avenue, Toronto, Ontario M5G 2C4. telephone 416-340-4800 ext 8422, Fax 416-340-5047 e-mail jconly@torhosp.toronto.on.ca route conversion and identification of patient populations in whom oral therapy would not be suitable. Appropriate oral alternatives to formulary injectables was also provided.

A pre-program audit of 27 patients (28 infections) indicated that $79(41 \%)$ days of intravenous therapy could have been substituted with oral therapy had the conversion criteria been applied. The same population was audited several weeks post-program implementation. The results of the post-program audit indicated that $49(26 \%)$ days of intravenous therapy could have been substituted with oral therapy. This represented a $36 \%$ reduction in days of intravenous therapy.

Based on the above findings it was estimated that potential savings of approximately $\$ 400,000$ could be attained with hospital-wide implementation of the program.

The formal plan for antimicrobial therapy route conversion was presented to the pharmacy and therapeutics committee. It subsequently received endorsement from the medical advisory committee and hospital administration. The plan included the reduction in total antimicrobial expenditure as well as the addition of one full time pharmacist to coordinate and facilitate the program for all 1100 plus beds. Because of a manual tracking system and the large size of the institution it was not difficult to convince anyone of the value of obtaining the resources required to coordinate this program. Our pharmacists were already performing the function but additional savings could be realized if the program were more formal and aggressive.

Once approved, the dollars were removed from the drug budget. Since expenses are allocated to the end user, each nursing unit's antimicrobial budget was reviewed. Areas such as the operating room, emergency, labour and delivery and psychiatry did not have a reduction to their drug budget for obvious reasons. Areas with high intravenous antimicrobial use had their budgets reduced accordingly.

A job description for a pharmacoeconomist was formulated and a person with an advanced degree was 
hired. The drug budget is continually monitored against the actual expense. Through six months of this fiscal year the targets have been met and we are currently almost $\$ 20,000$ under budget for antibiotic costs. Although not all the savings can be attributed to the route conversion program a significant proportion of the savings is thought to be as a result of the route conversion program. 


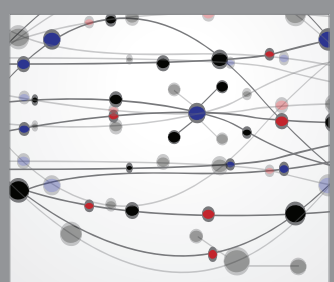

The Scientific World Journal
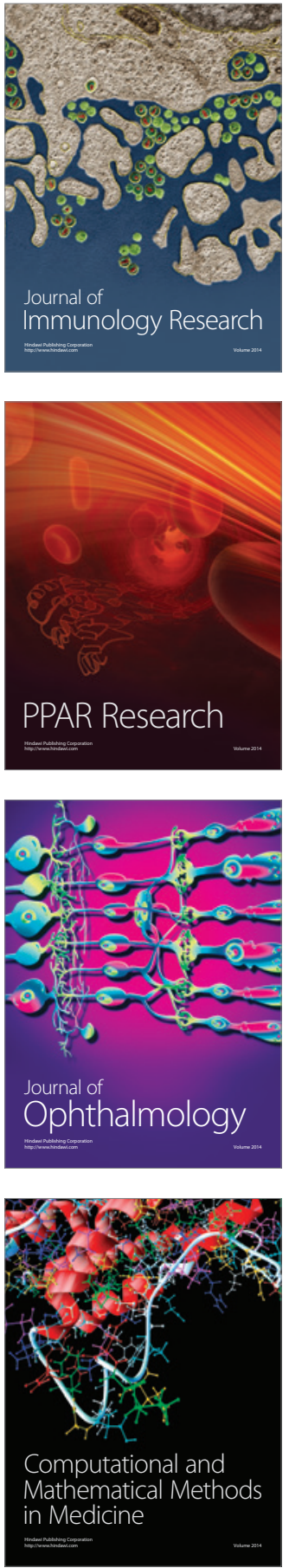

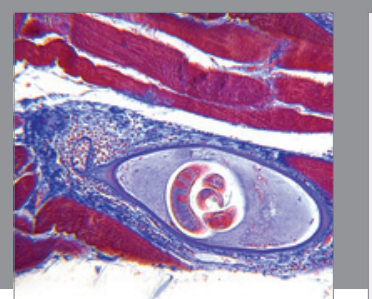

Gastroenterology Research and Practice

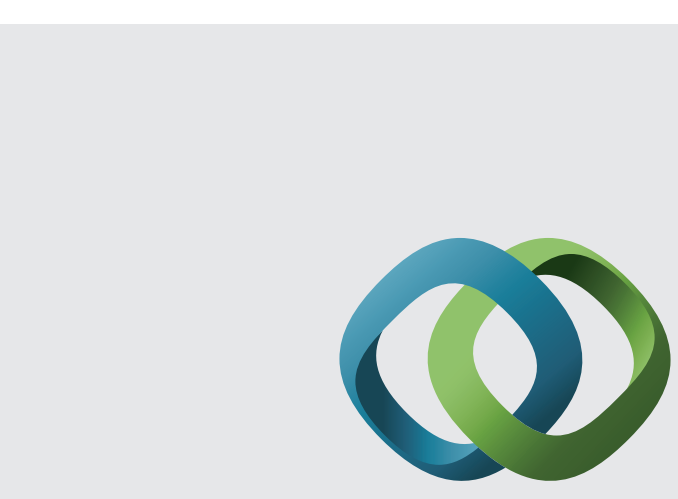

\section{Hindawi}

Submit your manuscripts at

http://www.hindawi.com
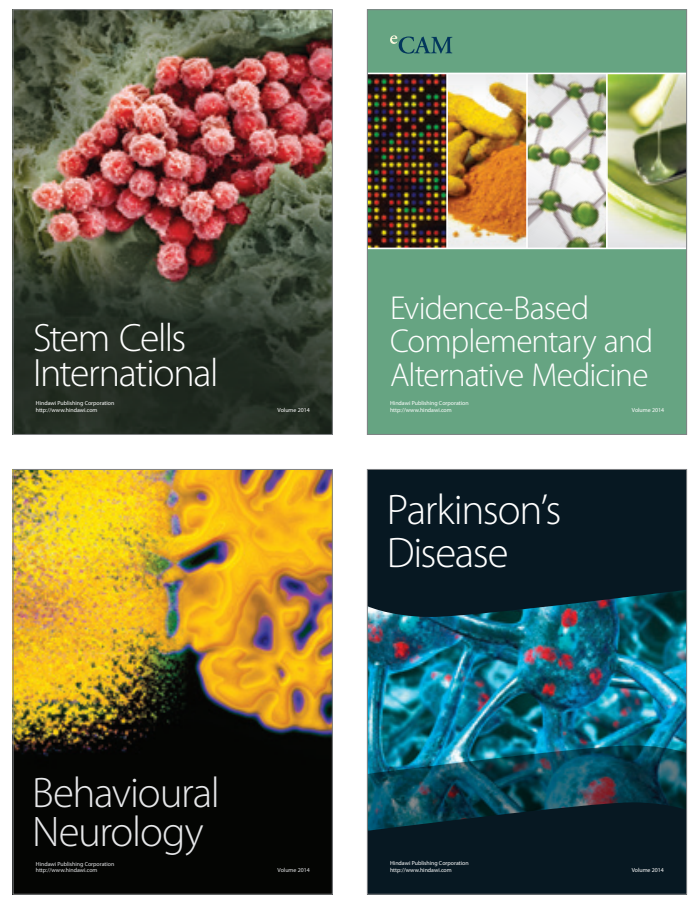
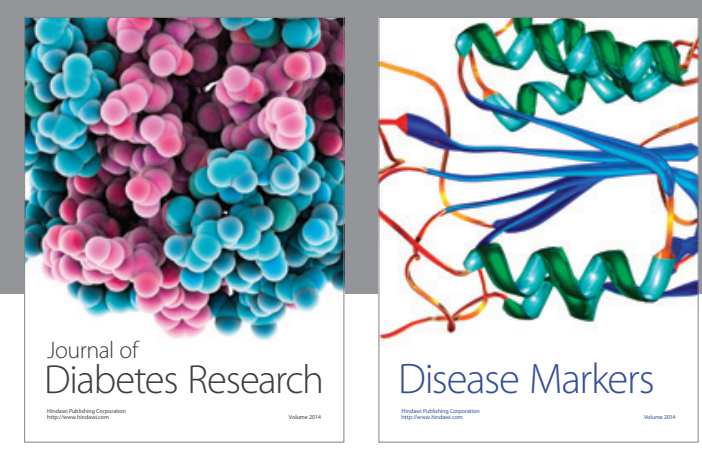

Disease Markers
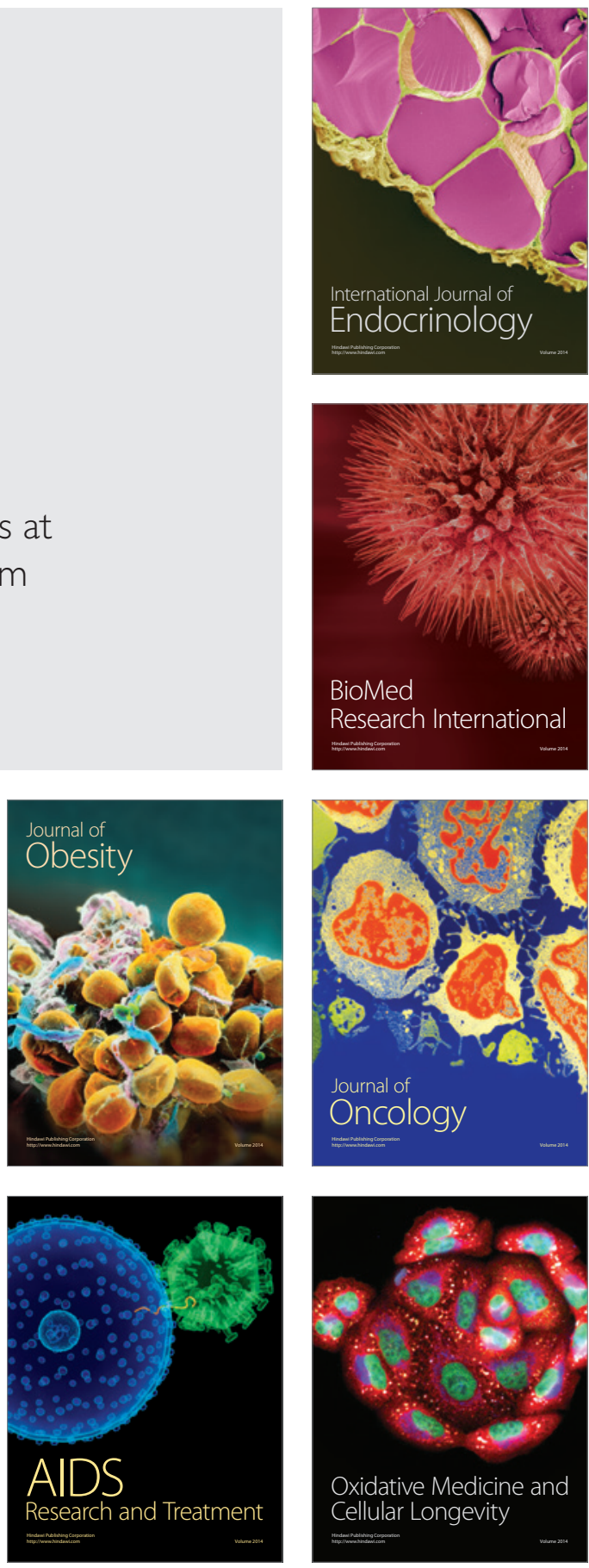